\title{
O AIKIDO E A CAPOEIRA COMO INSPIRAÇÃO PARA O TRABALHO DO ATOR
}

\author{
AIKIDO AND CAPOEIRA AS SOURCES OF INSPIRATION FOR THE \\ ACTOR'S WORK
}

Renata Mazzei Batista ${ }^{1}$

\section{Resumo}

Pretende-se neste artigo apresentar elementos da capoeira e do aikido como recursos para a preparação e para o trabalho criativo do ator. Trata-se de uma pesquisa em andamento cujo trabalho prático foi dividido em treinamento e criação - no primeiro, o ator se apropria de técnicas a fim de ampliar seu repertório e aprimorar habilidades físicas, no segundo, tudo o que foi experimentado no treinamento norteia as improvisações visando à construção de um resultado cênico. Como suporte a este processo recorremos aos pesquisadores Rudolf Laban, Alva Noe e Martin Buber.

Palavras-chave: aikido, ator, capoeira, criação, preparação

\section{Resumen}

Este artículo pretende introducir elementos de capoeira y aikido como recursos para la preparación y para el trabajo creativo del actor. Se trata de una investigación en curso cuyo trabajo práctico se dividió en la formación y la creación - en el primero, el actor se apropia de técnicas con el fin de ampliar su repertorio y mejorar las capacidades físicas, en la segunda, todo lo que se ha experimentado en la formación orienta la improvisaciones para construir un resultado escénico. Para apoyar este proceso recurrimos a los investigadores Rudolf Laban, Alva Noe y Martin Buber .

Palavras claves: aikido, actor, capoeira, creación, preparación

\begin{abstract}
This article intends to introduce elements of capoeira and aikido as resources for the preparation and for the creative work of the actor. This is an ongoing research whose practical work was divided into training and creation- in the first, the actor practices some techniques in order to expand his repertoire and improve physical abilities, in the second, all that has been experienced in training guides the improvisations in order to create a scenic result. To support this process we use the researchers Rudolf Laban, Alva Noe and Martin Buber.

Keyword: aikido, actor, capoeira, creation, preparation

\footnotetext{
${ }^{1}$ Escola de Comunicação e Artes da Universidade de São Paulo (ECA-USP). Doutoranda - pesquisa em andamento. Artes Cênicas. Orientação: Prof. Dr. Armando Sérgio da Silva. CAPES. Integrante do CEPECA (Centro de Pesquisa em Experimentação Cênica do Ator, ECA-USP). Professora de interpretação em curso profissionalizante e co-criadora da Das Duas Cia. De Teatro.
} 
$\mathrm{O}$ ator em seu fazer artístico necessita munir-se de recursos para desenvolver seu trabalho de maneira potente. Vemos esta potência refletida na beleza e na desenvoltura de seus movimentos, na organicidade das ações que cria, em seu repertório técnico e artístico, no estado cênico que estabelece e no preparo psicofísico que possui. Objetivando proporcionar maneiras para que essas necessidades sejam satisfeitas, recorremos ao aikido e a capoeira, duas artes marciais constituídas de elementos técnicos, culturais e artísticos que as tornam grandes fontes de inspiração para a elaboração de procedimentos que objetivam a preparação e a estimulação criativa do ator. Considerando que vivemos em um país onde a diversidade cultural é extremamente grande, estudar duas artes surgidas de contextos culturais tão diversos, mas que ao mesmo tempo fazem parte da identidade cultural brasileira, criando um diálogo entre elas, na tentativa de demonstrar que a combinação/mistura pode gerar elementos ricos para o trabalho no teatro, faz-se importante. Procuramos, dessa forma, nesta pesquisa, partir do que cada uma dessas artes marciais possui em sua essência, considerando tanto seus aspectos técnicos como culturais, identificando o que as diferencia e o que as aproxima, para então, apresentar ao ator um material rico de possibilidades o qual possa utilizar como suporte para construir um caminho poético e técnico firme e potente.

\section{O aikido e os princípios que o regem}

O aikido, fundado por Sensei Morihei Ueshiba, propõe a potencialização do $k i$, que é basicamente a energia vital que anima nosso corpo e o universo, por meio dos movimentos do corpo e da respiração. Segundo a filosofia oriental, que fundamenta as artes japonesas de forma geral, estamos em harmonia quando nosso ki está harmonizado com o $k i$ do próximo e do universo. Seguindo este raciocínio, Sensei Ueshiba criou o aikido que, como o próprio termo indica, significa de maneira bastante simplista o caminho (do) da harmonização (ai) com o ki. O fundador, conhecido como Ô Sensei (o grande mestre), afirmava que "os seres humanos devem unir a mente e o corpo, e o $k i$ que liga ambos, para então alcançar a harmonia com a atividade de todas as coisas do universo. Em virtude da sutil atividade do $k i$, harmonizamos a mente e o corpo, e a relação entre o indivíduo e o universo.” (UESHIBA, 1984, p.33). 
Sendo um grande conhecedor e praticante de diversas artes marciais, $O$ Sensei concebeu o aikido a partir de seus conhecimentos e experiências prévios visando não apenas a criação de uma forma de defesa, mas também de uma arte que proporcionasse desenvolvimento pessoal e autoconhecimento. Para tanto, duas foram as referências principais para a constituição do aikido: as técnicas do Daito-ryu e a religião Oomoto. Daito-ryu era a arte marcial praticada pelos samurais no período do Japão feudal e a religião Oomoto, existente ainda hoje e que forneceu a base para a estrutura ética do aikido, prega a existência de apenas um Deus universal e considera todos os seres humanos como iguais. A partir, portanto, destas concepções religiosas e técnicas, Ô Sensei concebeu uma arte marcial que tem como característica principal a cooperação entre os praticantes e a não competitividade. Sua prática é determinada pelo contragolpe, sendo, portanto, uma arte mais de defesa que de ataque. Aquele que contraataca recebe o nome de nage (em português significa aquele que dirige) e o que golpeia inicialmente de $u k e$. Quando o uke desfere um golpe contra o nage ou tenta imobilizálo, este se defende aproveitando a energia recebida do uke conduzindo-o para o seu centro com o objetivo de imobilizá-lo ou afastá-lo de si. Para o aikido o centro do corpo é considerado o ponto localizado cerca de cinco centímetros abaixo do umbigo, que é onde se encontra o centro de gravidade do corpo. Neste contato entre uke e nage a harmonização entre os dois corpos acontece.

Parece estranho falar em harmonia quando estamos tratando de uma atividade que pressupõe contragolpe e embate. Entretanto, faz-se importante destacar que não se trata de um embate, mas de uma conjugação de forças, de uma interação de energias por meio da execução de técnicas que favorecem ambos os participantes, uma vez que permite o aprimoramento dos dois corpos envolvidos no processo. Temos, portanto, nesse embate, um momento de intensa comunhão onde ambas as partes têm que estar abertas para perceberem o parceiro em sua integralidade, estabelecendo com ele uma forma de comunicação que se dá a partir da linguagem corporal. Surge, então, um diálogo vivo e orgânico por meio do corpo. Entretanto, esta interação harmônica apenas existe porque uke e nage apresentam qualidades de movimento opostas, o que faz com que estes opostos se interseccionem criando uma dinâmica natural, bela plasticamente e plena de energia.

Partindo do pressuposto que uke e nage apresentam qualidades de movimentos diferentes e por isso se harmonizam, entende-se, portanto, que se exigem 
habilidades diferentes de cada um deles. O nage, por ter a incumbência de conduzir o parceiro, deve estar sempre em posição estável, com postura alinhada e relaxada e deslocando-se no espaço de forma esférica, sendo o quadril seu ponto central. Deslizando os pés pelo chão (suri ashi) com joelhos semiflexionados o nage se movimenta a exemplo de um pião que gira em torno do próprio eixo. A esfericidade é fundamental nesta arte marcial, pois é ela que permite ao nage colocar em prática a força centrífuga quando este traz o uke para seu centro e a força centrípeta quando o projeta para longe de si. Para que toda esta dinâmica se instaure com eficiência é necessário que o nage tenha boa consciência de seu centro de gravidade e do uso da respiração. Já o $u k e$, quando é contragolpeado, tem sua estabilidade alterada para a instabilidade até a queda, uma vez que é projetado para longe do nage ou imobilizado por este no chão. Além disso, durante a intervenção do nage, a tensão excessiva da musculatura e os movimentos diretos utilizados pelo $u k e$ sofrem alteração passando para um relaxamento e uma flexibilidade maiores, possibilitando a harmonização entre os dois corpos que se conectam como um só. Neste momento o uke cede à proposta do nage e deixa-se ser conduzido por ele. Temos, portanto, que a resistência inicial do uke é quebrada e absorvida pela esfera dinâmica do nage. Este ponto é de extrema importância, pois se o uke se mantem resistente à proposta do nage, não se deixando levar pela esfera dinâmica, a fluidez não acontece, podendo um dos dois aikidoistas sofrer lesões físicas.

Percebe-se, pelo exposto, que a complementaridade de energias no aikido é de grande importância e se dá pela integração dos opostos. Nesse sentido temos, em resumo, na dinâmica do aikido, a estabilidade do nage e a instabilidade do uke, a agressividade inicial do $u k e$ com o relaxamento do nage, o controle do movimento do nage e a submissão do $u k e$, a manutenção do centro pelo nage e as torções no corpo do $u k e$, a esfericidade no espaço criada pelo nage e a esfericidade no corpo do uke e, por fim, a suavidade do nage em oposição à tensão do $u k e$.

\section{A capoeira e os princípios que a regem}

A capoeira é considerada uma luta-dança criada pelos escravos no Brasil com o objetivo de defesa e de entretenimento. Ela se constitui pelo jogo que se instaura entre dois capoeiristas no centro de uma roda formada por outros capoeiristas 
embalados pelo som de cantigas e toques compostos por instrumentos como berimbau, caxixi, atabaque e pandeiro. Durante o jogo os parceiros interagem entre si por meio de seus movimentos como se estivessem conversando impulsionados pelas músicas. O termo 'conversando' na capoeira é bastante apropriado, pois a interação entre os dois capoeiristas se dá como se estivessem perguntando e respondendo um ao outro por meio de seus corpos. Novamente a ideia de diálogo corporal, a exemplo do que ocorre também no aikido, se presentifica nessa interação constante e fluida. Dizemos constante porque uma vez no centro da roda, não se permite parar por nenhuma razão. E esta movimentação constante e fluida se dá principalmente pela ginga que é a movimentação básica da capoeira. Na ginga identificamos sinuosidade, molejo, agilidade, flexibilidade e estabilidade. Estas características permeiam todos os movimentos da capoeira que usam o corpo todo como um conjunto. Entretanto, deve-se destacar a importância do metatarso que auxilia o impulso e o molejo, do quadril que ajuda na estabilidade, na impulsão e na criação das alavancas e da coluna que deve estar sempre em posição adequada para a eficiência das técnicas.

O repertório de técnicas da capoeira é bastante vasto e contempla movimentos tanto de ataque como de esquivas. Identificamos também na capoeira uma boa utilização do espaço, dos níveis alto ao baixo, pois isto favorece a criação de estratégias durante o jogo tornando-o mais dinâmico e criativo. Faz-se importante, todavia, destacar que se encontra grande variação na realização das técnicas de grupos para grupos, tanto em relação ao que se executa como em relação à maneira de se fazer, pois a capoeira tem como importante característica a subjetividade em sua realização. Assim, é como se cada capoeirista deixasse em seu jeito de jogar sua impressão digital, sua pessoalidade. E esta abertura para a individualidade faz com que encontremos muitas variações entre as formas de se jogar capoeira pelo mundo afora. Entretanto, todas estas formas, comungam com princípios e elementos comuns que constituem a identidade desta arte marcial, fazendo dela uma arte rica de possibilidades técnicas e artísticas.

Outra característica da capoeira que merece grande ênfase é a música. Não se pode falar em capoeira sem abordar o componente musical aliado ao movimento. As músicas que ouvimos durante uma roda como ladainhas, quadras e corridos ${ }^{2}$, criam uma

\footnotetext{
${ }^{2}$ A música na Capoeira pode ser classificada em quatro tipos:
} 
atmosfera que impulsionam o capoeirista, influenciando seus movimentos e conduzindo-o a um estado de ânimo específico.

Neste ponto é importante discorrer um pouco sobre a relação da música com o estado emocional do ser humano. Desde o ventre materno, o som nos afeta diariamente exercendo forte influência sobre nosso comportamento e nosso estado emocional. Fillat afirma que "a memória sonora gera durante nossas vidas uma infinidade de relações com nossa psique, estabelecidas à base de rastros ou impactos emocionais que, ao longo de nossa existência, vão criando um arquivo de sons. Este arquivo é formado por experiências próprias e códigos culturais herdados." (2011, p.29; tradução nossa) No caso da capoeira, uma arte afro-brasileira, este arquivo musical é resultado da cultura africana trazida para o Brasil em seu período colonial mesclado com a realidade brasileira desde a época da chegada dos escravos até os dias de hoje. Desde o surgimento da capoeira, os toques e os cantos têm profunda conexão com o andamento do jogo, não sendo possível falar de um sem o outro. Da mesma forma, também, não podemos dissociar a música dos movimentos executados pelos capoeiristas. Isto porque quando tratamos da música, não nos referimos apenas ao sentido da audição, mas a todo o sistema sensorial que compõe o corpo humano. Por causa desta interconexão do corpo todo, os sons acabam por afetar nosso imaginário, nossas emoções, nossas ideias e, por consequência nossos movimentos. A esse respeito, Meelberg explica que

A música é criada por movimentos humanos, música consiste de movimentos sônicos, e os ouvintes são tanto metaforicamente quando literalmente movidos pela música. Consequentemente, movimento e gesto são vitais para entender o que é a música, como ela é produzida e o que ela pode fazer. ${ }^{3}$ (2011, p.127; tradução nossa).

Ladainha: É tocada na capoeira angola na abertura da roda. Tem um ritmo mais lento que as demais, e tem o tom de oração e de lamento. Na ladainha costuma-se contar a história de uma figura importante do universo da capoeira como, por exemplo, Zumbi dos Palmares ou de um acontecimento relevante como a Guerra do Paraguai quando os capoeiristas forma enviados para ajudar no combate.

Corrido: é uma cantiga que "acelera" o ritmo e que se caracteriza pela pergunta do puxador e a resposta do coro. São estrofes curtas e ágeis.

Quadra: é uma estrofe curta de quatro versos e seu conteúdo pode variar de acordo com a criatividade do compositor.

Chula: é uma cantiga curta, normalmente feita de improviso que faz apresentação ou identificação.

3 "Music is created by human movements, music consists of sonic movements, and listeners are both metaphorically and literally moved by music. Consequently, movement and gesture are vital in trying to understand what music is, how it is produced, and what it can do." (MELBERG, 2011, p. 127) 
Temos, por consequência, que, se toda música está intrinsecamente conectada ao conceito de gesto e de movimento físico, ao discorrermos sobre um tipo de música como o da capoeira que nasceu entrelaçada a tipos específicos de movimentações, não é possível considera-los separadamente, uma vez que, desde suas origens, estas manifestações artísticas coexistem, dando forma a uma única manifestação cultural.

Reforçando ainda a afetação da música sobre o ser humano, convém ressaltar seu aspecto subjetivo que, assim como de todas as artes, se justifica no processo de incorporação, de concretização das ideias e das coisas que nos cercam. Quando estruturamos alguma ideia, o fazemos a partir de nossas experiências pessoais e da forma como nosso corpo internaliza estas informações. Portanto, não é possível desconectar a criação da música à experiência que a originou. Acerca disso, NOGUEIRA argumenta que:

(...) A constituição do objeto musical origina-se de nossas capacidades imaginativas - tais como esquematizações e projeções metafóricas. Se a música oferece uma representação, não é uma representação da experiência objetiva, mas do nosso entendimento dessa experiência. $\mathrm{O}$ valor da música assenta-se na qualidade das experiências do seu entendimento, envolvidas nos atos de criação, execução e recepção. Aquilo que a música pode comunicar não é, meramente, um pensamento, mas uma experiência (NOGUEIRA, 2003, p. 3).

Pode-se compreender pelo exposto, portanto, que a capoeira é uma arte marcial formada por uma complexa estrutura que traz em sua constituição aspectos técnicos, sonoros, sensoriais, ancestrais, da memória, somados ainda a subjetividade do praticante que capta com seu corpo toda essa dimensão e a torna visível e concreta no momento do jogo. Identificamos assim, elementos objetivos e subjetivos operando conjunta e harmonicamente e dando forma a esta arte marcial brasileira.

\section{$O$ corpo nesta pesquisa}

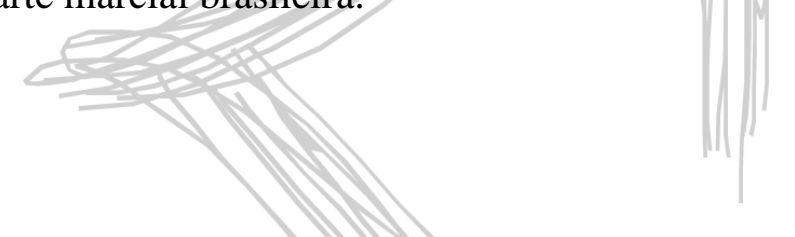

Neste artigo, nos referimos ao corpo de maneira integral, entendido em todos os aspectos físicos e psíquicos. Consideramos como aspecto físico toda a estrutura que dá forma ao corpo como ossatura e musculatura. Neste caso entendemos como 
forma o contorno definido pela massa corporal do indivíduo que se desenvolve no espaço em trajetórias retas ou circulares. A parte psíquica é entendida nesta pesquisa como sendo os impulsos internos gerados pelo corpo em movimento e pelos sentidos como ideias, sensações e imagens mentais. É neste conjunto vivo e dinâmico que o trabalho criativo dos atores se apoia. Pensando nesta unidade corporal, partimos da concepção de que o corpo como um todo deve estar engajado no menor movimento, potencializando, assim as ações criadas pela concentração de energia proveniente deste conjunto. Seguindo este pensamento, Laban explica que:

O corpo é nosso instrumento de expressão por via do movimento. O corpo age como uma orquestra, na qual cada seção está relacionada com qualquer uma das outras e é uma parte do todo (...) Cada ação de uma parte particular do corpo deve ser entendida em relação ao todo que sempre deverá ser afetado (...) (LABAN, 1978, p. 67)

Complementando a concepção de que o corpo é uma unidade psicofísica, Laban ainda explica que:

\begin{abstract}
A extraordinária estrutura do corpo, bem como as surpreendentes ações que é capaz de executar, são alguns dos maiores milagres da existência. Cada fase do movimento (...) cada simples gesto de qualquer parte do corpo revela um aspecto de nossa vida interior. Cada movimento se origina de excitação interna dos nervos, provocada tanto por uma impressão sensorial imediata quanto por uma complexa cadeia de impressões sensoriais previamente experimentadas e arquivadas na memória. Esta excitação tem por resultado o esforço interno, voluntário ou involuntário, ou impulso para o movimento. (LABAN, 1978, p. 49)
\end{abstract}

Assim, seguindo a concepção apontada por Laban (1978) de que existe uma conexão entre a impressão sensorial, a realização dos movimentos e a vida interior de cada um, aproveitamos como estímulo para a criação, a forma como o corpo todo é afetado pelos elementos trazidos pelo aikido e pela capoeira. Portanto, não se trata apenas de um simples aprendizado de movimentos novos, mas de como os atores se apropriam desses elementos novos e de como eles reverberam pelo conjunto corporal. Por esta razão, todo o contexto cultural e técnico destas artes marciais é utilizado como disparador para o processo prático desta pesquisa, possibilitando uma ampliação na expressividade criativa.

Completando o entendimento sobre a conexão físico-psíquica do corpo, convem esclarecer que algumas linhas de investigação da ciência cognitiva como a psicologia e a neurocência começam a aceitar que a forma como a cognição se dá, assim como a maneira de se processar as ideias, não estão centralizados apenas no cérebro e 
que o aspecto psíquico não está desconectado do físico. Os pensamentos, as emoções e as reações físicas não são unicamente resultados de uma atividade cerebral que controla o restante do corpo, pois o corpo e os fenômenos que nele se processam são resultados da integração corpo e mente.

Buscando fundamentação a esse raciocínio recorremos a Alva Noe, cujos estudos seviram de referência a essa pesquisa. Noe (2010) explica que nós não somos unicamente nosso cérebro e que interagimos todo o tempo com o meio ambiente por meio do nosso corpo. Segundo este filósofo, a mente não é alguma coisa dentro de nós e que funciona como uma máquina de calcular, pois se a experiência é ver, sentir, ouvir e pensar, então a mente não é algo que se processa dentro de nós, mas algo que fazemos. Noe segue explicando que se a consciência é aquilo que fazemos, e a percepção é o processo pelo qual nos tornamos conscientes das coisas e das pessoas a nossa volta, então percepção é ação. Temos, portanto, que, se todas as nossas experiências e ações estão conectadas à forma de percebermos o mundo, quando nos colocamos em momentos de experimentações e de vivências novas, o que fazemos será diretamente afetado. Assim, pensando na relação deste fenômeno com o trabalho do ator, e considerando o vasto leque de elementos técnicos, culturais e artísticos presentes no aikido e a capoeira, uma janela de possibilidades se abre para diferentes experimentações psícofísicas das mais variadas quando se recorre a estas artes marciais como fontes de inspiração.

\section{Os princípios do aikido como contribuição para o trabalho do ator}

Dentre as diversas qualidades que identificamos na prática do aikido, alguns aspectos foram selecionados para o desenvolvimento do trabalho prático com os atores: autoconhecimento, potencialização na expressividade corporal, variação em relação à qualidade de movimento, cooperação e não competitividade e conexão com o parceiro.

Neste trabalho o autoconhecimento e a ampliação da potencialidade expressiva estão caminhando juntos, uma vez que o aprofundamento do conhecimento sobre o próprio corpo conduz o ator a uma maior autonomia e eficiência em seu processo de criação. Neste processo de aprimoramento pessoal, o estudo sobre as qualidades de movimentos propostas pelo aikido teve uma importância fundamental, pois possibilitou aos atores uma ampliação de repertório e uma melhor apropriação das 
novas técnicas. Para auxiliar esse processo recorremos a Rudolf Laban (1978) que investigou o movimento em profundidade considerando o corpo tanto em sua parte física como psíquica. Dessa forma, partimos dos aspectos relativos às ações corporais apontados por ele como peso (variação de tônus do leve ao pesado), espaço (direto e flexível; níveis espaciais) e fluência (controlada e liberada) ${ }^{4}$ e os aplicamos no treinamento como meio de abordar as técnicas selecionadas desta arte marcial. Desta forma no que diz respeito à fluência identificamos que a do $u k e$ é liberada enquanto a do nage é controlada; em relação ao peso, o nage utiliza tônus leve enquanto o uke sofre uma transformação de energia passando do pesado para o leve durante o desenvolvimento da relação com o nage; em relação ao espaço, o uso dos níveis alto, médio e baixo aparece em todos os movimentos já que a trajetória esférica descendente é recorrente na movimentação do nage.

Enfocando particularmente a relação entre uke e o nage, outros aspectos estão sendo aproveitados para o trabalho do ator que são: a cooperação, a nãocompetitividade e a conexão entre os parceiros. Estes princípios são colocados juntos porque na prática é impossível separá-los. Ou seja, se um ator está em relação direta e cooperativa com o outro, a conexão se instaura. Para o ator a "escuta" em cena é fundamental, escuta esta considerada da forma mais ampla possível, abarcando não só o que é falado, mas o que é realizado corporalmente em seus mínimos detalhes. Os dois parceiros se colocam em um fluxo de dar e receber constantes, sendo que um depende diretamente do outro para criar. É nesta relação direta que a conexão se instaura.

\section{Os princípios da capoeira como contribuição para o trabalho do ator}

A capoeira tem duas grandes características que são: a conexão da música com o movimento e o diálogo corporal entre os parceiros. Em um jogo de capoeira a

\footnotetext{
${ }^{4}$ Nesta investigação entendemos por tônus o grau de força muscular empregado na realização de um movimento. Dessa forma, seguindo aspectos elementares às ações corporais elaborados por Laban, consideramos pesado o movimento que emprega força muscular intensa, e leve o movimento que necessita de um grau de tensão próximo ao do relaxamento. Em relação ao Espaço, Laban utiliza o termo direto para se referir a uma atitude interna do agente, ou seja, o agente foca toda sua atenção corporal em um único ponto no espaço. Por sua vez, flexível é o movimento que se caracteriza por ocupar um espaço tridimensional simultaneamente. Ainda em relação ao fator Espaço, Laban apresenta três possibilidades de níveis, tendo como critério a alturas, que são: baixa, média e alta (Rengel, 2005, p. 63 a 71). Por fim, Laban apresenta como outro fator a fluência, que diz respeito à continuidade do movimento do agente, podendo ser liberada ou controlada.
} 
música e os movimentos dos capoeiristas se confundem, sendo um o impulsionador do outro. Neste processo de intersecção entre os jogadores ao som de toques e cantos uma dança vai se configurando. E nesta dança observamos desenvoltura e "escuta corporal". Na capoeira o termo "escuta" se mostra mais presente do que nunca já que "pergunta" e "resposta" são termos correntes nessa arte marcial. Nesse sentido, um verdadeiro diálogo corporal acontece. Os dois jogadores devem manter o fluxo do jogo promovendo uma "pergunta" com seu corpo e "ouvindo" a resposta. Nesta pesquisa, esta dinâmica de diálogo corporal em fluxo constante está sendo levada para o trabalho de preparação e de criação dos atores que devem manter-se em contato um com o outro todo o tempo, a exemplo do que ocorre no centro de uma roda de capoeira.

Acrescente-se ainda que, todo o estudo sobre as qualidades de movimento a partir dos conceitos de Rudolf Laban realizado com as técnicas do aikido, também foi feito com os movimentos da capoeira justamente para que a apropriação pelos atores destes elementos novos fosse mais eficiente. Dessa forma, estudando os golpes e as esquivas da capoeira durante um jogo, percebemos que o uso do espaço pelo jogador é multidirecional uma vez que, desde que não se perca a relação com o parceiro e que não se rompa o círculo estabelecido pela roda, os movimentos podem explorar os níveis alto, médio e baixo, e se desenvolver na vertical, horizontal e diagonal. Em relação à fluência, na maior parte do tempo, os movimentos são controlados e estáveis. A circularidade que encontramos no aikido, também está presente em toda a dinâmica desta arte brasileira. Além disso, o tônus utilizado durante o jogo é sempre firme e relaxado, ampliando assim a prontidão e a disponibilidade corporal. Por fim, os movimentos da capoeira favorecem também o condicionamento e o aprimoramento da coordenação motora já que todo o corpo é mobilizado como um todo.

\section{A relação a partir do Eu-Tu}

Um ponto que recebe grande atenção nesta pesquisa, conforme já foi indicado anteriormente, é a relação criada entre os parceiros e a consequente potencialização da comunicação que se dá entre eles durante a dinâmica da prática. Como embasameto teórico para melhor compreensão deste aspecto relacional, recorremos ao filósofo e teólogo Martin Buber que desenvolveu teorias a respeito da relação do homem com que está a sua volta concebendo as palavras princípio Eu-Tu e 
Eu-Isso. Para Buber, o ser humano, a partir do momento que nasce cria vínculos e interage com o que o cerca necessariamente. E é nessa criação de vínculos que surge o Eu-Tu que dá existência ao mundo da relação e que para ser proferida necessita da reciprocidade e da totalidade do ser. Ela é direta, sem mediações.

Buber, em contraste ao Eu-Tu, apresenta a palavra princípio Eu-Isso que se refere ao mundo da experiência, da utilização, do conhecimento, da observação. Para ele, quando o homem se aprofunda na experimentação, ele perde a relação. Buber explica então que o:

Eu da palavra-princípio Eu-Tu é diferente do Eu da palavra-princípio EuIsso. $\mathrm{O} \mathrm{Eu}$ da palavra-princípio Eu-Isso aparece como egótico e toma consciência de si como sujeito (de experiência e de utilização). O Eu da palavra-princípio Eu-Tu aparece como pessoa e se conscientiza como subjetividade. (BUBER, 1974, p.73)

Podemos entender, assim, que existem duas formas de se relacionar com o que está à volta, sejam coisas ou pessoas. Em um caso temos dois seres que se conectam mutuamente e sem antecipações. Este é um momento de presença onde a comunicação acontece de maneira direta, mas não necessariamente com palavras. Quando nos entregamos a esta relação, o fazemos com o corpo todo, deixando de existir o Eu separado do Tu. Neste caso os dois passam a formar uma totalidade.

\section{Explicando esse pensamento, Buber (1996) expõe:}

O propósito da relação é a relação em si - no contato com o Tu. Assim que entramos em contato com o Tu, nós somos tocados por um sopro da vida eterna.

Quem se coloca em relação participa de uma atualidade, quer dizer, em um ser que não é meramente parte dele e nem está meramente fora dele. Toda atualidade é uma atividade da qual participo sem me apropriar dele. Onde não há participação, não há atualidade. (...) Quanto mais diretamente o Tu é tocado, mais perfeita é a participação. ${ }^{5}$ (1996, p. 112, 113, tradução nossa)

Em oposição ao exposto acima, o Eu na conexão com o Isso sai da relação de entrega e passa a ser um observador. Aquele ou aquilo que está em contato com o Eu é apenas um objeto de estudo. $\mathrm{O}$ Eu, com este intuito, não participa, não interage com o objeto, mas age sobre ele, o manipula, o experimenta. Existe, por consequência, apenas o Eu que toma iniciativa sobre o mundo, ou seja, o Eu age enquanto o Tu simplesmente

\footnotetext{
5 "The purpose of relation is the relation itself - touching the You. For as soon as we touch a You, we are touched by a breath of eternal life. Whoever stands in relation, participates in an actuality; that is, in a being that is neither merely a part of him nor merely outside him. All actuality is an actuality in which I participate without being able to appropriate it. Where there is no participation, there is no actuality.... The more directly the You is touched, the more perfect is the participation.” (BUBER, 1996, p. 112, 113).
} 
recebe esta ação. Por isto, Buber define o Eu do Eu-Isso como "egótico", conforme exposto a seguir:

A pessoa diz: "Eu sou"; o egótico diz: "É assim que eu sou". "Conhece-te a ti mesmo" significa para a pessoa: conhece-te como ser. Para o egótico quer dizer: conhece o teu jeito de ser. Se afastando dos outros, o egótico se distancia do Ser.(...) A pessoa contempla o seu si-mesmo; o egótico ocupa-se com o seu "meu" : meu jeito, minha raça, meu agir, meu gênio. ${ }^{6}$ (1996, p. 113, 114, tradução nossa).

Buber esclarece também que ninguém está o tempo todo na relação Eu-Tu e nem no Eu-Isso. O homem no decorrer de sua vida transita de um estado para outro constantemente, embora uns estejam mais focados na pessoalidade e outros mais no ego. "E é nessa transição de um para outro que a verdadeira história acontece"” (1996, p. 115, tradução nossa).

Buber defende, portanto, que, quanto mais uma pessoa se centra no diálogo, na busca do genuíno encontro com o outro, entregando-se para este momento, sem a preocupação de prever ou impor nada, mais a palavra princípio Eu-Tu é proferida. Nesta relação não existe o passivo e o ativo, o que age e o que recebe a ação, pois essa dinâmica acontece simultaneamente durante a relação entre os dois. Entretanto, quanto mais a pessoa se centra em si mesmo, se separando do outro ou tendo no outro apenas um objeto de experimentação, mais ele empobrece sua dimensão humana dialógica.

Estabelecendo um paralelo entre o aikido e a capoeira e as teorias de Martin Buber aqui expostas, identificamos importantes conexões entre eles, tendo em vista que, o que estas artes marciais focam primordialmente é a relação entre os parceiros e com o que está no entorno, o momento presente e a potencialização destes encontros. Assim, por meio do suporte teórico exposto, trabalhamos na sala de ensaio aspectos que colocam os atores em uma sintonia mais fina e mais harmônica com quem ou com aquilo que estiver envolvido, maximizando qualitativamente seu trabalho. $\mathrm{O}$ resultado que se busca com esse processo é uma comunicação mais eficiente e uma estimulação mais potente de um ator para outro.

\footnotetext{
6 “The person says', 'I am'; the ego says, 'That's how I Am'. 'Know Thyself' means to the person: Know yourself as being. To the ego it means: know your being-that way. By setting himself apart from others, the ego moves away from being. ... The person beholds his self; the ego occupies himself with this My: my manner, my race, my Works, my genius.” (BUBER, 1996, p. 113, 114).

7 “ (... ) Between these and those true history takes place."
} 
A fim de elucidar melhor a relação entre o que está sendo estudado teoricamente e o que está sendo realizado na prática, convém relembrar algumas informações importantes já expostas sobre o objeto em estudo para então vinculá-las ao suporte teórico apresentado. Durante a prática do aikido, conforme já foi explicado, o aikidoista só produz um movimento quando há outro vindo em sua direção para que este interaja. Assim, ele não deve se preocupar em estabelecer combinações com o parceiro, pois ambos precisam estar disponíveis para que haja uma interação genuína. Temos, assim, um encontro direto e imediato, onde ocorre a troca de energia de um para outro, afetando-se reciprocamente. À semelhança do aikido, a capoeira tem seu foco na relação entre os parceiros que "perguntam" e "respondem" simultaneamente e em fluxo contínuo durante o jogo. O jogo, portanto, está diretamente ligado à presença efetiva de todos os envolvidos e à potência do que é realizado na roda. Com essa conexão entre os dois jogadores, potencializada pela energia gerada pela roda formada por pessoas que tocam e cantam, um efetivo diálogo corporal acontece, estando a combinação prévia excluída deste lugar. Sendo assim, a presença e a sintonia entre os parceiros ganha força.

Percebemos, dessa forma, nas duas artes marciais citadas a conexão do indivíduo $(\mathrm{Eu})$ com o entorno, seja coisa ou pessoa $(\mathrm{Tu})$, passando a fazer parte de um todo que o afeta e que é afetado por ele em um movimento de inter-relação constante. Assim, ao pensarmos nos procedimentos práticos para o trabalho com os atores, tomamos estas ideias como ponto de partida, e experimentamos jogos e exercícios com foco relacional, onde o momento presente é o mais importante, devendo toda a criação se desenvolver disso, seja com contato físico ou não. Busca-se nesses processos, portanto, que todas as antecipações e preparações sejam descartadas pelos atores que devem focar toda a sua atenção na relação com o outro e no momento presente.

\section{Alguns esclarecimentos sobre o desenvolvimento da prática}

Conforme se observou, o aikido e a capoeira têm características muito diferentes entre si no que diz respeito às origens culturais, às qualidades de movimento, à forma de se conectar com o parceiro, às regras que dão ordem à prática e à relação com o espaço. Entretanto, elas têm também pontos em comuns que são: potencialização do autoconhecimento, uso do corpo como um conjunto único, uso de trajetórias 
circulares e instauração de relações vivas e dinâmicas entre os parceiros que permite uma comunicação intensa por meio do corpo. Foi a partir desses princípios que elaboramos procedimentos visando o aprimoramento do trabalho do ator.

A prática que está sendo desenvolvida com um grupo de atores recémformados abarcou dois momentos distintos: treinamento e criação. No treinamento algumas técnicas e princípios destas artes foram selecionados para que os atores compreendessem a essência. Tendo em mente esses princípios, começou-se a trabalhar com improvisos primeiramente individuais e em seguida em dupla, trio e assim por diante até chegar num grande improviso com todos os atores. Desses improvisos estão sendo levantados materiais artísticos que estão dando forma ao resultado cênico pretendido. Vemos o improviso em muitos tipos de expressões artísticas, mas sua importância para o teatro é indiscutível. Desde seu início o teatro usa o improviso como recurso para estimular o ato criativo. Nesta pesquisa estamos considerando como improviso a habilidade do ator de criar e se adaptar a circunstâncias novas, deixando que os elementos novos façam parte de seu estado pessoal.

Dessa forma, munidos de todo o repertorio técnico e artístico proporcionado pela capoeira e pelo aikido, com o suporte dos pesquisadores apresentados, caminhamos do treinamento, visando a ampliação de repertorio e a preparação corporal, para a improvisação - utilizada como forma de desenvolver a expressividade artística dos atores, de potencializar as relações e de levantar material poético para a criação das cenas.

\section{Considerações finais}

Apreende-se, pelo exposto que, pretendemos com esta investigação, por meio de procedimentos práticos ancorados nos elementos oferecidos pelo aikido e pela capoeira e auxiliados pelo suporte téorico-prático aqui apresentado, auxiliar o ator na transposição do corpo cotidiano para um corpo cênico, ampliando seu repertório técnico e artístico, potencializando as relações, estimulando a criatividade e aprimorando o autoconhecimento. Entendemos, assim, que, experimentar estas artes marciais conjuntamente, deixando evidentes suas similaridades e contrapontos, permitindo que o participante experiencie ambas as possibilidades para, a partir disso, inician a sua criação e compor um texto cênico, possa ser enriquecedor para o trabalho do ator. 
Bibliografia

BUBER, Martin. I and Thou. Trad. Walter Kaufmann. New Tork: Touchstone, 1996.

Eu e Tu. Trad. do Alemão por Newton Von Zuben. São Paulo: Ed. Moraes. 1974.

FILlAT, Josep M. Romero. M de Música, del Oído a La Alquimia Emocional. Tapa Blanda: Alba Editorial

LABAN, Rudolf. Domínio do Movimento. Tradução de Anna Maria Barros de Vecchi e Maria Silvia Mourão Netto. $4^{\mathrm{a}}$ ed. São Paulo: Summus, 1978.

MEELBERG. Vicent. In New Perspectives on Music and Gesture, edited by Anthony Gritten and Elaine King, p. 127-129. Farnham: Ashgate, 2011

NOE, Alva. Out of Our Heads. Why You Are Not Your Brain, and Other Lessons from the Biology of Consciousness. NY. Farrar, Straus and Giroux Inc. 2010

NOGUEIRA, Marcos. 2003. O imaginário metafórico da escuta. Semiosfera - Revista de Comunicação e Cultura, no. 4-5. Disponível em http://www.eco.ufrj.br/ semiosfera/anteriores/semiosfera45/conteudo_imag_mnogueira. htm.

REGO, Waldeloir. Capoeira Angola: Ensaio Sócio Etnográfico. Salvador: Ed. Itapuã. 1968.

RENGEL, Lenira. Dicionário Laban. $2^{a}$ ed. São Paulo: Annablume, 2005.

RENGEL, Lenira. Os temas de Movimento de Rudolf Laban. São Paulo: Annablume, 2008 .

SILVA, Eusébio Lôbo da. O Corpo em Ação na Capoeira, Campinas: UNICAMP, 2008. Vol. 4.

UESHIBA, Kisshomaru. O Espírito do Aikido. Tradução de Euclides Luiz Calloni. $6^{\text {a }}$ ed. São Paulo: Cultrix, 1984.

UESHIBA, Moriteru. The Aikido Máster Course. Best Aikido 2. Tradução para o inglês de John Stevens. Tokyo: Kodansha International, 2003.

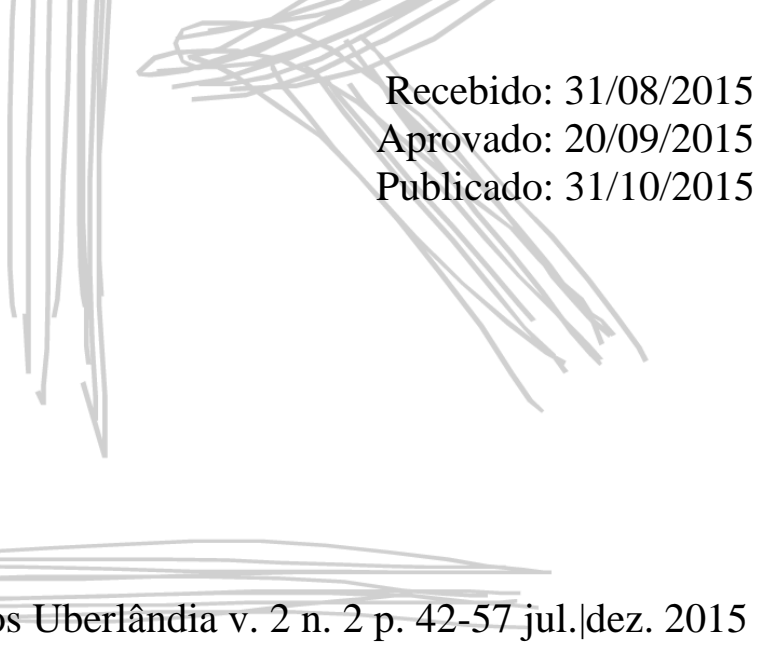

